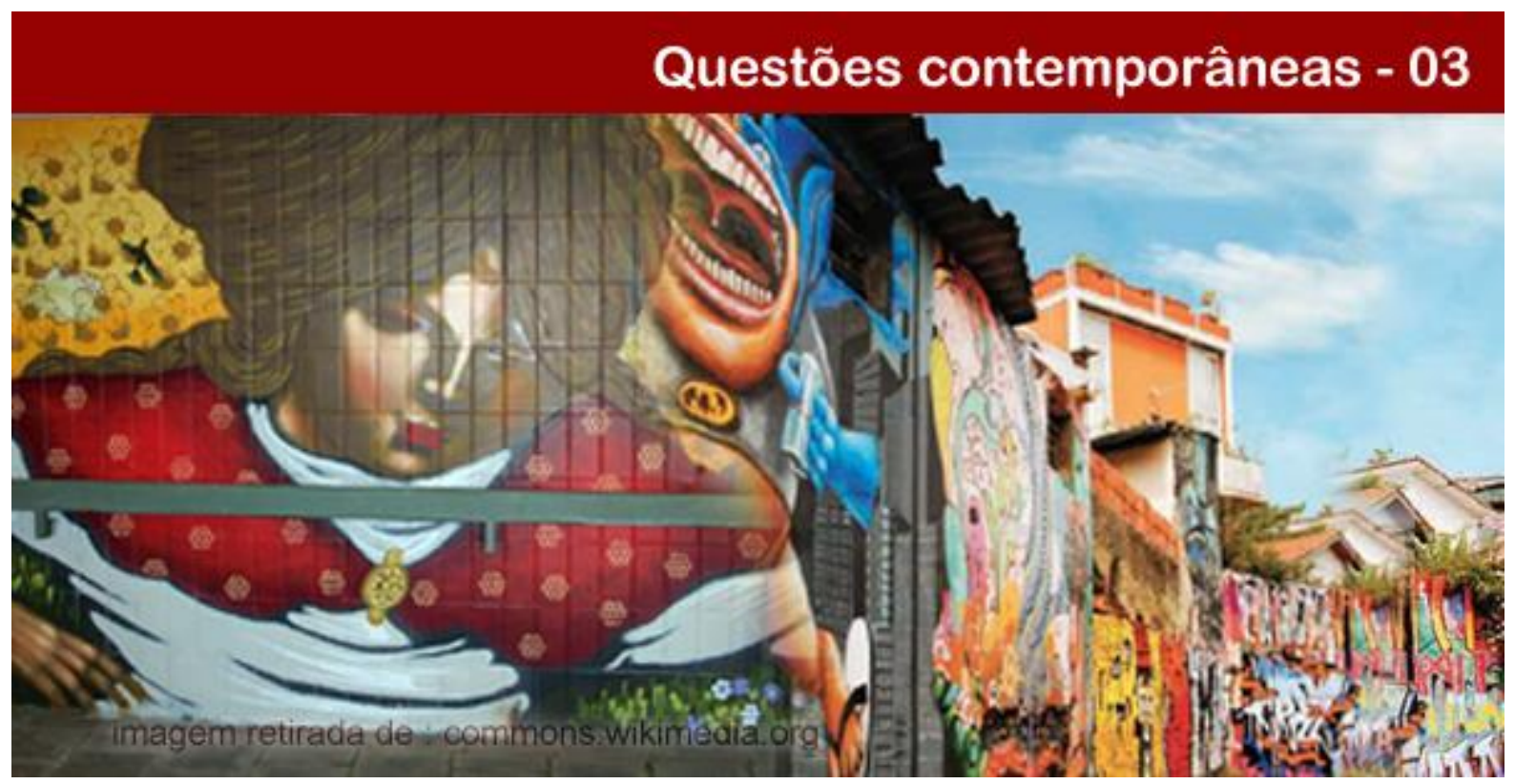

\title{
ARTE EM ESPAÇOS NÃO CONVENCIONAIS: GRAFITE COMO FORÇA MOTRIZ DA APROPRIAÇÃO DO ESPAÇO PÚBLICO URBANO
}

\section{Elisa Reifschneider}

Doutoranda de Psicologia Ambiental no Departamento de Psicologia Social, do Trabalho e das Organizações (PSTO) da Universidade de Brasília (UnB). Psicóloga clínica do Centro de Atendimento e Estudos Psicológicos (CAEP) da UnB.

Resumo: Este artigo tem por objetivo explorar as possibilidades de apropriação do espaço público pela população urbana a partir da presença do grafite. Inicialmente é feita uma conceituação do grafite, distinguindo-o dos demais signos gráficos e textuais presentes em suportes urbanos. Em seguida, são apresentados significados sociais, políticos e econômicos desta arte, explicitando a dinâmica que se instaura entre a arte não sancionada e a ordem vigente de ocupação do espaço público. Por fim, são abordadas as possibilidades do grafite enquanto agente promotor de apropriação do espaço público pela população das cidades, a partir da interação entre a técnica e o suporte físico desta arte com as possibilidades críticas e interpretativas do espectador-participante.

Palavras-chave: Grafite. Arte de rua. Apropriação. Espaço público.

\section{ART IN UNCONVENTIONAL SPACES: GRAFFITI AS A DRIVING FORCE OF THE APPROPRIATION OF URBAN PUBLIC SPACE}

Abstract: The purpose of this article is to explore the possibilities of appropriation of public space by city dwellers through graffiti art. Initially this art form is conceptualized in order to distinguish it from other graphic signs and texts present in urban structures. Subsequently, its social, political and economic meanings are introduced, indicating the dynamics established between unsanctioned art forms and the prevailing occupation of public space. Finally, the possibilities of graffiti art as a driving force in the appropriation of urban public spaces by its inhabitants are explored, taking into consideration the interaction between the technique and physical media of this art form and the critical and interpretative possibilities of the viewer-participant.

Keywords: Graffiti art. Street art. Appropriation. Public space.

"Arte que não é hegemônica por uma razão ou outra pode precisar de algum tipo de introdução verbal para ser percebida". 
(ALMENBERG, 2010, p.ix, tradução nossa).

\section{Introdução}

A decoração das fachadas de edifícios e casas de cidades brasileiras é uma prática antiga. São visíveis azulejos, cores vibrantes na fachada (geralmente janelas e portas), vitrais, calçadas com padronagem, cobogós e diversos outros materiais que personalizam o espaço de seu dono - seja ele pessoa física, jurídica ou o Estado. Coexistem com essas personalizações uma multitude de escritos e desenhos em fachadas cegas, muros de propriedades privadas e na superfície de equipamentos públicos, em sua maioria feitos por pessoas que não detém a posse legal daquele território. Estes escritos e desenhos, ditos graffitis, estão presentes na maioria das cidades brasileiras, compondo a imagem dos centros urbanos e suscitando, do ponto de vista do observador, uma série de questões quanto à legalidade e valor social, estético e econômico destas manifestações, estando sujeitos ao apreço ou à crítica da população que frequenta os espaços em que estas grafias se dão.

Neste texto o uso da palavra grafite remete somente ao grafite-arte, com predominância de imagens de clara intenção artística. O termo graffiti é mais amplo e está sendo utilizado para fazer referência a qualquer signo gráfico, textual ou visual, não publicitário/corporativo, no espaço público. Portanto, engloba a pichação, o grafite-arte e as práticas intermediárias. Cabe ressaltar, entretanto, que na literatura não há um consenso sobre o uso destas nomenclaturas.

O graffiti e as demais intervenções nas fachadas e vias urbanas suscitam um questionamento a respeito do que Kevin Lynch chamou de as cinco dimensões dos direitos espaciais, trabalhadas por Carr, Francis, Rivlin e Stone (1992) a partir de possibilidades ligadas às liberdades de acesso ao lugar, de ação neste lugar, de apropriação do lugar e de mudança de posicionamento e destinação dos elementos que compõem este lugar.

$\mathrm{O}$ acesso é constituído por três componentes. O acesso físico é a habilidade de entrar em um lugar que seja bem conectado com o entorno e sem barreiras. Em contrapartida, o acesso visual é aquele que permite ter visibilidade da rua sobre as oportunidades e ameaças encerradas naquele espaço em que se pretende entrar, gerando uma harmonia entre a expectativa de privacidade e de segurança. Já o acesso simbólico diz respeito à presença de dicas (indivíduos específicos ou elementos de design) que sugerem as atividades e públicos bem-vindos naquele local (CARR et al., 1992).

\section{POLÊM!CA | Revista Eletronica da Uerj}


A partir do acesso concedido ou obtido, a ação que se pode dar em um lugar também está condicionada às diferentes demandas de grupos distintos (dominantes, minoritários e os donos e gestores do espaço) e às regras, regulamentos e acordos sociais vigentes. No espaço público estão presentes grupos de características sociais, históricas, étnicas e financeiras diversas, com filiações religiosas e políticas variadas, e diferentes motivações e interesses na utilização do espaço comum. Estes diferentes grupos reivindicam e se apropriam de espaços ao afirmar um controle territorial e de privacidade sobre um lugar, gerando possibilidades de interferência neste para seus propósitos (CARR et al., 1992). Vários destes grupos praticam o graffiti.

O uso não sancionado das superfícies públicas, fundamentalmente, questiona, de forma intencional ou não, a legitimidade dos donos e gestores do espaço público, especialmente na sua prerrogativa de definir qual tipo de material comunicacional pode figurar na arena pública - seja este material publicitário, político, de utilidade pública ou de expressão individual ou grupal. Como detalha Campos (2008, p.6):

\begin{abstract}
O espaço é pontuado por uma materialidade que remete para a autoridade do Estado na gestão da mobilidade (sinais de trânsito, transportes públicos, etc.) e do espaço urbano (diferentes funcionalidades do território, parques, jardins, espaço edificado, etc.), na preservação das ideologias oficiais (monumentos consagrados a pátria e aos seus heróis), que remete para o poder de determinados agentes privados na comunicação (publicidade em cartazes, outdoors, etc.), e na modelação do espaço (edifícios privados), mas que revela, igualmente, dinâmicas transgressoras (graffitis, construção clandestina, vandalismo, etc.).
\end{abstract}

Dentro deste contexto, este trabalho procura explorar de que maneira o grafite-arte, como tipo específico de manifestação no espaço público, coloca-se não só como possibilidade de expressão dos grupos de sua autoria, mas também como facilitador da apropriação do espaço público pelo city dweller: o cidadão comum que habita e faz uso das cidades.

Para tanto, esta investigação abraça uma visão transdisciplinar do grafite, posto que os elementos para a compreensão do lugar social desta prática no espaço urbano encontram-se na interseção da psicologia ambiental, da sociologia, da semiótica e da arte. No desenvolvimento das interpretações aqui expostas, foram utilizadas diversas fontes documentais, tais como repositórios online de fotos de grafite ${ }^{1}$, livros e artigos especializados na análise do grafite e em entrevistas com grafiteiros, o extinto repositório de artigos sobre cibercultura e

\footnotetext{
${ }^{1}$ Disponível em: http://streetartsp.com.br/, http://home.ekosystem.org/, www.streetsy.com, http://unurth.com/, www.graffiti.org/.
}

\title{
POLÊM!CA | Revista Eletronica da Ueij
}


intervenção urbana rizoma.net ${ }^{2}$ e histórias de vida de pichadores ${ }^{3}$, bem como avaliação in loco de grafites na cidade de São Paulo.

$\mathrm{Na}$ busca de entender o grafite como processo comunicativo e empoderador, esta investigação encontra sustentação teórica principalmente no conceito de apropriação da psicologia ambiental e no modelo analítico de Armando Silva (1987), explorados em maiores detalhes ao longo do texto.

\section{O que é grafite}

Em primeiro lugar, torna-se necessário delimitar de que grafite se trata. Este define-se pelo espaço físico que ocupa e pela efemeridade de sua duração; faz uso tanto de "signos plásticos (cores, formas e texturas) quanto signos linguísticos e signos icônicos (analógicos e figurativos)" (SILVEIRA, 2006, p. 11); permite graus variados de interação com o público e transita entre os campos de transgressão pública e arte sancionada. Finalmente, por ter pouca durabilidade, está estreitamente ligado ao registro fotográfico e divulgação na mídia digital (SENO 2010; CAMPOS, 2008).

São temas recorrentes nesta arte o questionamento da realidade consensual, da cultura do consumo e da propriedade privada; a transgressão de espaços psicológicos (SENO, 2010); a formação da identidade e o incentivo implícito à retomada das ruas pela população. No Brasil, vê-se a valorização da identidade nacional no trabalho de diversos grafiteiros como Nunca, Derlon, Criola, Os Gêmeos e Highraff, entre outros, que resgatam tradições regionais (como a literatura de Cordel), lendas e folclore, as origens étnicas do povo brasileiro e o sincretismo religioso, tão característico do país.

Javier Abarca (2011) aponta a característica principal desta arte em ser pública, de rua. Ela pode ser independente ou oficial, a depender da ausência ou existência de autorização para sua execução naquele local. Ser ou não sancionada influencia profundamente sua execução. Arte oficial muitas vezes tem acesso a financiamento, materiais de qualidade e tempo para execução, mas em troca se submete à burocracia e aprovação prévia. Arte independente precisa arcar com todos os custos sozinha, muitas vezes tendo acesso somente a materiais precários. Trabalha ainda de forma acobertada, escondida, podendo ser

2 Os textos compilados do portal rizoma.net podem ser encontrados no endereço: http://virgulaimagem.redezero.org/rizoma-net/.

${ }^{3}$ Entrevistas do caixão, do site Túmulos: http://entrevistastumulos.blogspot.com. 
interrompida. No entanto, detém maior liberdade de ação. Sua mensagem não é sujeita a censura prévia e não está vinculada ao sistema institucional.

Cabe notar que a distinção entre pichação e grafite é em si controversa. A pichação teria como características principais a predominância de textos em preto e branco, o privilégio das formas e explorações caligráficas (SILVEIRA, 2006), uma postura agressiva em relação ao resto da sociedade (MANCO, ART \& NEELON, 2005), um formato reivindicatório e politizado, e ainda um forte caráter de afirmação identitária (CAMPOS, 2008), de demarcação do espaço. A pichação ignora o habitante comum como audiência e busca o reconhecimento e respeito de seus pares (ABARCA, 2011). Um exemplo típico é o "pixo reto", ou tag reto, da região de São Paulo: linhas e curvas angulosas em tinta preta formando palavras praticamente ilegíveis. De outro lado, o grafiteiro visa comunicar-se com a sociedade em sua amplitude e, para isso, faz uso predominante de imagens coloridas, figurativas ou abstratas, explorando as tonalidades utilizadas. Esta prática tem intenção estética e artística (SILVEIRA, 2006), ainda que com mensagem politizada, e encontra uma tolerância ou até apreço social (MANCO, ART \& NEELON, 2005).

Figura - 1: À direita da imagem, visão parcial de um mural de grafite de Eduardo Kobra, na rua Henrique Schaumann, em São Paulo. À esquerda da imagem, grafite de artista não identificado, com pichação sobreposta.

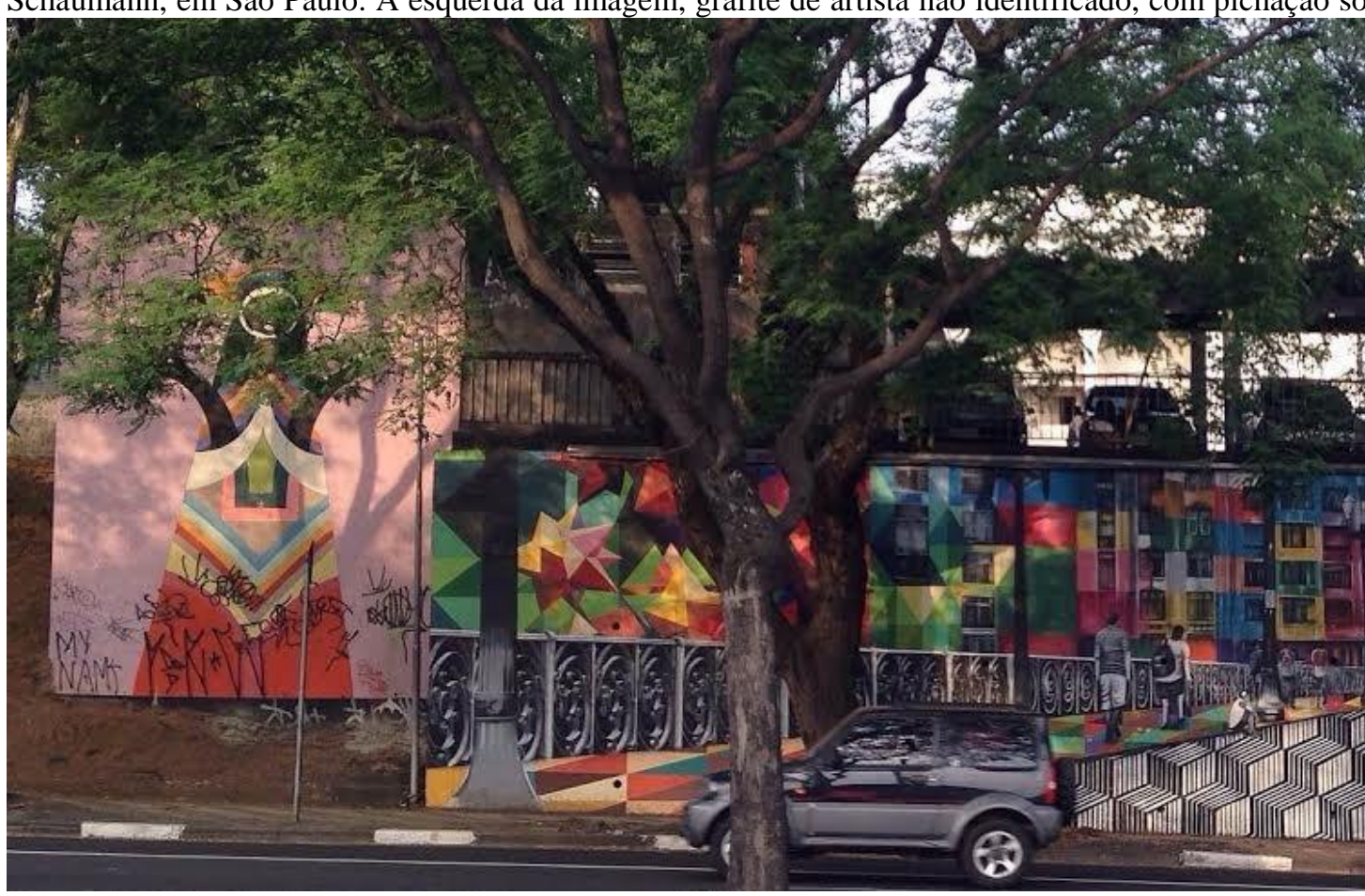

Fonte: REIFSCHNEIDER, E. Sem título. 2014. Fotografia digital. 
No entanto, a distinção entre pichação e grafite permanece em grande parte didática (SILVEIRA, 2006). As manifestações encontradas resistem a uma categorização inflexível. Em parte, porque diversos grafiteiros transitam entre as duas categorias (MANCO, ART \& NEELON, 2005), têm trabalhos na pichação e não necessariamente abandonam a primeira ao se envolver com a segunda. Em parte, porque são numerosas as formas dos graffitis e estas alastram-se de maneira muito rápida, sobrepondo-se e borrando as fronteiras com o ativismo, a arte, a linguagem publicitária e o vandalismo (SILVEIRA, 2010).

Entrevistas com pichadores, reproduzidas por membros desta mesma subcultura (TÚMULOS, 2009) indicam ainda que embora a pichação seja uma tipografia comum, existem grandes variações quanto à motivação e intencionalidade desta prática, desde a defesa de que este é um movimento politizado reivindicatório até a constatação de que dispõe de um funcionamento similar a um vício, ou ainda, é um resultado da falta de equipamentos públicos para jovens em situação de vulnerabilidade.

De qualquer maneira, há indícios de que, independente da intenção inicial dos autores e para além de seu valor tipográfico, a grafia comumente entendida como pichação é vista pelo restante da sociedade como vandalismo (MANCO, ART \& NEELON, 2005) e encontra pouquíssima aprovação social, constituindo um sistema fechado compreensível somente para pessoas que participam dele. Por este motivo a pichação é impermeável à apropriação pelo grande público, ao contrário do grafite.

Em termos de abrangência, no Brasil o grafite exerce uma predominância absoluta sobre outras formas de arte urbana, ainda pouco reconhecidas pelo público e documentadas pela academia. Este tipo de grafite (que faz uso predominante de imagens e exclui o pixo reto e demais pichações claramente identificadas) tem efeitos na sociedade para além da simples oposição e precisa ser compreendido para que possa ser bem usufruído.

O modelo analítico de Armando Silva (1987) trata principalmente dos graffitis textuais e é anterior à revolução digital. No entanto, tem forte apelo para a exploração inicial do grafite-arte a partir das esferas de análise que delimita. Este autor coloca que a compreensão do graffiti se organiza ao redor de sete elementos ou valências que caracterizam esta prática: a marginalidade (da mensagem veiculada e do público a que se destina), o anonimato, a espontaneidade, a cenificação, a precariedade (de materiais), a velocidade e a fugacidade (tempo reduzido de duração da obra). As valências de marginalidade, anonimato e 
espontaneidade seriam anteriores à execução do graffiti e comporiam predisposições necessárias do indivíduo que realiza esta prática. As próximas três valências seriam operativas, dizendo respeito ao momento em que o graffiti é feito. Finalmente a última valência, fugacidade, é referente a uma consideração do que se passa com o graffiti após a sua confecção e é dependente de aspectos ambientais e das ações do governo e de outros cidadãos.

Para cada uma das valências há um imperativo correspondente. O imperativo estético é retratado na cenificação, o imperativo econômico informa a precariedade da prática e o imperativo instrumental está ligado à velocidade da tarefa. $\mathrm{O}$ imperativo ideológico sustenta o anonimato, o imperativo psicológico fundamenta a espontaneidade e o imperativo comunicacional está ligado à marginalidade da mensagem e do público. Finalmente o imperativo social sustenta a fugacidade.

Um graffiti prototípico é, portanto, feito de forma anônima, marginal e espontânea, de maneira rápida e com instrumentos precários, embora o local, formato e cores utilizadas sejam escolhidos de forma estratégica. Por fim, a obra dura pouco tempo, estando sujeita às intempéries e intervenções de outros agentes. A presença ou ausência destes elementos é que vai caracterizar um escrito ou desenho como estando dentro ou não do sistema do grafite urbano. Portanto, ao não possuir inteiramente estas valências, o grafite-arte seria uma forma intermediária de comunicação, que não está plenamente no campo do proibido.

\section{A dinâmica do grafite no espaço urbano}

Um dos locais com maior concentração de grafite na cidade de São Paulo, por exemplo, conhecido como o Beco do Batman, tem a função não de transgredir, mas de apresentar. Suas ruas (Gonçalo Afonso e Medeiros de Albuquerque, no bairro da Vila Madalena), cujas fachadas cegas são cobertas por desenhos, dizem: este é o grafite, estas são as possibilidades que esta linguagem possui ${ }^{4}$. Tentar categorizar o significado do tipo de intervenção que o Beco aponta nos coloca diante da fluidez de sentidos presentes e da dificuldade de encerrá-los em uma compreensão única. Tomados de maneira isolada, já finalizados, sem acesso ao processo de sua construção e manutenção, os desenhos do Beco

\footnotetext{
${ }^{4}$ Um outro local com função similar é a Avenida 23 de Maio, cujos grafites, que ocupam mais de 15 mil metros quadrados, podem ser visualizados aqui: http://geekness.com.br/mural-de-grafite-na-23-de-maio/.
}

\section{POLÊM!CA | Revista Eletronica da Ueij}


são formalmente identificáveis como grafite: no estilo, nas cores, em boa parte do conteúdo. No entanto, em seu processo se distanciam de várias valências anteriormente apresentadas. $\mathrm{O}$ anonimato e a espontaneidade dos desenhos são reduzidos, não há precariedade nos materiais utilizados nem qualquer necessidade de velocidade ou encobrimento para a prática, visto que a arte no beco é sancionada. Alguns grafites lá permanecem por muito tempo, sugerindo ainda algum tipo de manutenção.

Observa-se também uma mudança de perspectiva no significado geográfico daqueles desenhos. O Beco do Batman tem este nome devido ao primeiro grafite encontrado ali, na década de 80. Conta a história que este grafite chamou a atenção de alunos de artes plásticas que começaram também a desenhar nas paredes próximas. Hoje o Beco já foi incorporado pela sociedade de consumo. Campanhas comerciais filmam ali. Galerias de arte fazem visitas monitoradas e pagas ao Beco, eventos são promovidos aproveitando-se os desenhos como fundo, ensaios fotográficos são realizados. Em resposta a este movimento, quem, em tese, se pretendia transgressor entra na negociação. Ricardo Rosas, influente ciberativista já falecido, que compilou diversos textos de contracultura disponíveis no portal rizoma.net, explicita bem: "o mercado recupera mesmo aqueles que o desafiam dentro de suas diretrizes" (ROSAS, 2002, p.9). Artistas do Beco cobram direitos autorais para a exibição de suas obras comercialmente e processos judiciais já foram movidos pela utilização indevida da arte ${ }^{5}$. Nisto é preciso reconhecer que o Beco do Batman se aproxima de uma galeria, ao ar livre, com as peculiaridades que este contexto encerra, mas ainda uma galeria.

Figura - 2: Beco do Batman, SP

\footnotetext{
5 De acordo com reportagem de Paulo Toledo Piza para o Portal G1 em 26/04/2012, disponível em: http://g1.globo.com/sao-paulo/noticia/2012/04/artistas-de-sp-cobram-cache-por-foto-publicitaria-com-grafiteem-beco.html.
} 


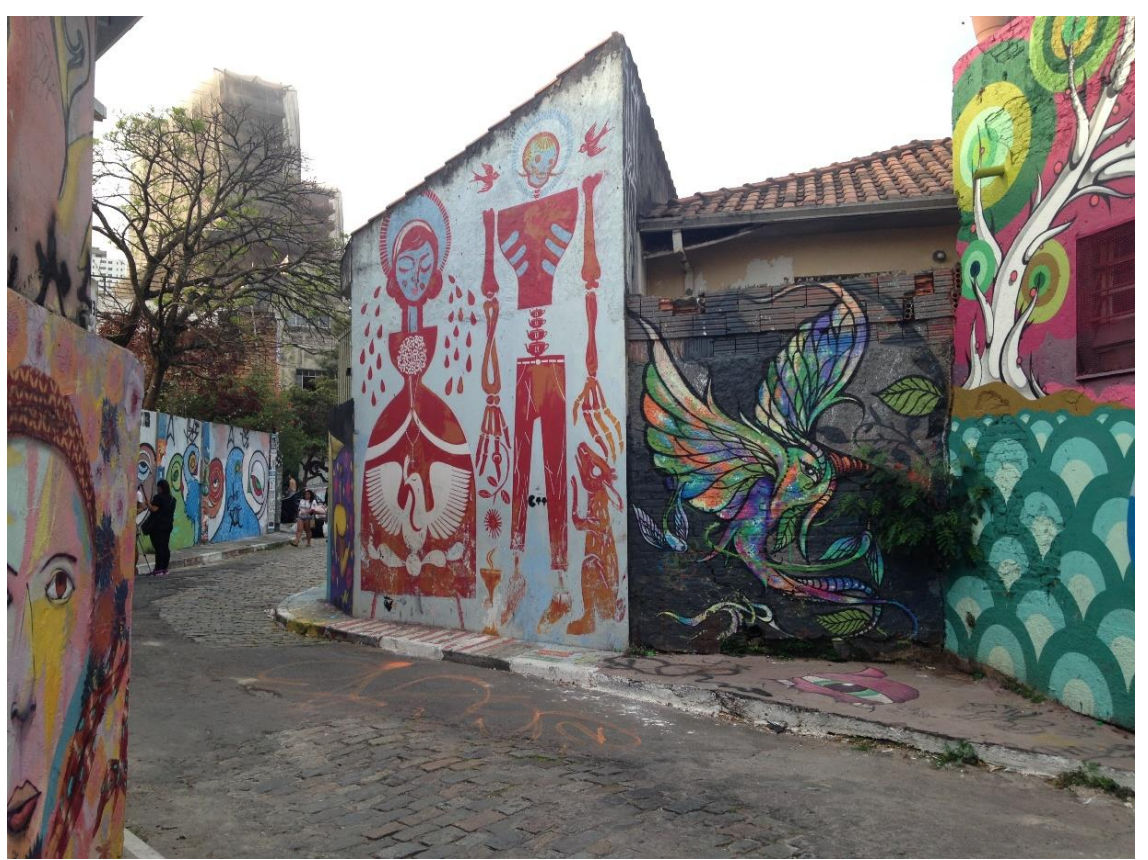

Fonte: REIFSCHNEIDER, E. Beco do Batman. 2014. Fotografia digital.

A arte urbana, nesta função de se comunicar com um público mais amplo, perde a característica de marginalidade completa da mensagem. Ela também deixa de ser espontânea, visto que diversos murais são autorizados pelo dono do espaço, quiçá até planejados conjuntamente. Os murais têm ainda em sua maioria um traço identificável e assinaturas visíveis, fugindo do anonimato. Todavia, mesmo que não cumpra com as principais valências pré-operativas descritas por Silva, o grafite-arte permanece com um forte componente subversivo e crítico.

Uma dinâmica mais ampla parece estar em jogo no espaço público. O grafite surge como contestador da ordem vigente e transgride regras e espaços. Em seguida o capitalismo coopta as técnicas da arte de rua e transporta seus signos e linguagens para o mercado: leva o grafite para o museu, para as lojas, para os comerciais. A arte subverte esta nova mensagem: grafiteiros realizam intervenções em outdoors (a exemplo do sequestro visual, do francês ZEVS), espalham (como Une Nuit, Tom Tom e L'Atlas) novos outdoors de grafite utilizando a linguagem da publicidade, se utilizam (como o Eduardo Srur ${ }^{6}$ ) da máquina da mídia para obter publicidade para seus projetos. A mídia então dá notoriedade a artistas e intervenções

\footnotetext{
${ }^{6}$ De acordo com entrevista concedida a Fernando Luna para a Revista Trip em 05/06/2006. Disponível em: http://revistatrip.uol.com.br/revista/salada/guerrilha-urbana.html
} 
específicos, influenciando como são percebidos. E assim, neste jogo, alternam-se as tensões do dominante e do marginalizado, sucessivamente.

\section{Grafite como força motriz da apropriação do espaço urbano pelo cidadão comum}

Para o escopo de avaliar o grafite como promotor de apropriação do espaço, não interessa tanto a classificação que se dá a ele e sim as possibilidades de interação com o público que estes grafites despertam. É importante salientar que uma maior aprovação pública dos desenhos não se traduz diretamente na compreensão da mensagem que o autor desejava transmitir e da vivência de quem a originou (SILVEIRA, 2006). Silva (1987) argumenta que o que está representado na parede interage com o enquadre dado pelo espectador e, portanto, seu significado é construído nesta interação entre desenho e possibilidade interpretativa do receptor. A partir da história, vivência, valores e práticas deste último se desenrolam diversos tipos de olhar: do moralista que de imediato salienta o aspecto proibido do graffiti e não enxerga a mensagem, até o olhar cúmplice em que a pessoa "vê na parede o seu ponto de vista" (SILVA, 1987, p.71), estando implicada naquela mensagem.

O grafite não se limita aos muros e à tinta normal. Ocupa cada vez mais espaços e materiais novos. Ele está nos bueiros e esgotos nos desenhos abstratos de Zezão, nas figuras resultantes da retirada da poluição das superfícies (o chamado grafite reverso), no uso de tintas visíveis somente com um espectro específico de luz, na técnica do desenho em 3D. A medida em que ocupam espaços, abrem também novas dimensões de diálogo.

Ainda que o grafite tenha uma interatividade inerentemente restrita, visto ser somente um desenho na parede, sem partes móveis, cabe ao espectador decidir seu nível de envolvimento. Grafiteiros geralmente possuem diversas obras em uma mesma cidade e o olhar atento do espectador pode decodificar trabalhos do mesmo autor e temas recorrentes entre autores diversos (SILVA, 1987), possibilitando uma análise mais ampla das mensagens veiculadas. Desta maneira, dois processos complementares de apropriação estariam presentes: apropriação por ação/transformação por parte do grafiteiro e, também, pelo público, a apropriação por identificação: simbólica, cognitiva, afetiva e interativa (CAVALCANTE \& ELIAS, 2011).

Embora mais limitado do que outras vertentes de arte urbana, o grafite encontra possibilidades de ação participatória do público para além da reflexão e identificação com a 
mensagem ou a crítica desta. Nesse sentido destacam-se trabalhos como o de El Tono e Nuria, Influenza e Candy Chang. El Tono e Nuria propõem algo similar a um caça-tesouro onde o público deve encontrar e decifrar inúmeras variações de seus logos artísticos na cidade (MANCO, 2004). Estes se parecem com chaves e fechaduras, são complementares e formam trilhas pela cidade. Já Candy Chang apresenta instalações urbanas que fazem uso da tinta na parede de forma mais participativa e se completam somente a partir da informação deixada pelo transeunte. Before I Die (2011) é um destes exemplos. Trata-se de uma lateral de parede que é pintada com inúmeras repetições da frase "antes de morrer eu quero........". São deixados à disposição materiais necessários para que o público complete as frases da forma como quiser.

Por fim, como exemplo de uma interação mais ativa e transgressora está o jogo The Art of Urban Warfare (a arte da guerra urbana), proposto em 2002 pelo grafiteiro Influenza, o holandês Jeroen Jongeleen. Ele convida qualquer pessoa a escolher uma de três cores prédefinidas (azul, verde ou marrom) para um exército urbano. Por meio de stencils de soldadinhos de chumbo na cor escolhida a pessoa deve conquistar e defender territórios de sua cidade de outros jogadores desconhecidos que participem do mesmo jogo. As regras são comuns e disponíveis na internet. O exército cuja cor se tornar mais visível no bairro indica o vencedor. Em que pese a depredação da propriedade privada envolvida nesta proposta, esta apropriação literal das ruas e ocupação de territórios públicos por meio deste jogo foi documentada em mais de 40 cidades. Cabia ao público colocar o jogo em prática, a partir do acesso às instruções e stencils disponíveis na página da internet, que por fim acabou sendo apagada sob suspeitas de terrorismo ${ }^{7}$.

Propostas desta natureza possibilitam uma interação direta com o espectador, permitindo com que este exerça escolhas estratégicas (intelectuais) e estéticas e possibilitando diferentes experiências sensoriais. Bourriaud (2009) defende a "elaboração coletiva do sentido" da obra de arte a partir de um observador-participante, que não recebe o objeto de arte pronto, mas participa na sua realização. O objeto da arte passa a ser o processo de sua confecção. Cada vez mais a arte de rua incorpora este espírito e gera produções que escapam à classificação.

\footnotetext{
${ }^{7}$ De acordo com informações do site Módart, disponível em: http://www.modart.com/2012/03/25/the-art-ofurban-warfare/.
} 
Ainda que o grafite não seja tão efêmero quanto às performances urbanas pontuais, ele partilha muitas vezes do mesmo desejo de inserir (por um breve momento, pela duração de um olhar) uma quebra na realidade consensual, questionando as normas e ordem vigentes, instigando a crítica social e política, questionando o transeunte a respeito de sua inserção na sociedade (como indivíduo e grupo) e incorporando um objeto estético na trama da periferia ou de locais deteriorados, onde não há qualquer expectativa que este exista. $\mathrm{O}$ grafite exige que quem o visualiza note o ambiente circundante e se questione sobre o uso de elementos e equipamentos urbanos (ABARCA, 2011). Em suma: faz o outro pensar. Este funcionamento se aproxima do que Fernando Cocchiarale (2005, p.18) chamou de virótico, reportando-se ao sentido de grupos de artistas que realizam intervenções públicas e passageiras: “elas invadem sistemas codificados por normas estabelecidas para colocá-los em pane, para questioná-los em suas entranhas, pô-los em curto-circuito, ainda que por instantes".

A sobrecarga de informações que a cidade nos dá gera uma necessidade de automatizar os comportamentos e emudecem a percepção do ambiente, mas um grafite bem colocado quebra esta mecânica, sensibiliza o usuário do espaço, faz com que este reflita sobre o manejo do espaço público, sua privatização, controle e agenda. Dentro desta perspectiva o grafite toma posicionamento no velho dilema da arte de existir por si só ou exercer papel político. O grafite-arte tem potencial de comunicar a um amplo grupo por não ameaçar como primeira estratégia, como o faz a pichação, com seus traços agressivos desprovidos de cor. Por sua beleza e técnica os desenhos convidam o olhar em vez de agredí-lo e ganham nisto alguns segundos para transformar; desalienar o espectador, chamando sua atenção para assuntos contemporâneos importantes e ainda, por sua mera existência, chamando a atenção para as possiblidades de uso do espaço urbano.

Resta saber os efeitos mais amplos deste funcionamento. Talvez ao apresentar o grafite para o grande público desta maneira mais acessível, ele abra campos de atuação e sensibilidades, ajude a promover os desenhos, a ressignificar espaços, a rever leis que em muito limitam a apropriação das áreas públicas. Talvez venham a ter o efeito oposto, de excluir grafites que não sejam tão grandiosos, bem executados, bem posicionados ou aqueles que tenham conteúdo mais politizado, mais agressivo. Ambos são trajetos dentro de uma ampla escala de possibilidades para a compreensão do grafite urbano, onde talvez a opinião pública possa exercer um grande papel de influência.

\section{POLÊM!CA | Revista Eletronica da Ueij}




\section{À guisa de conclusão}

A arte de rua evidencia as oportunidades e obstáculos que o espaço público traz para a vivência da fronteira entre individualidade e coletividade dentro da ordem social e econômica vigente. Documentação e teorizações sobre esta temática não são facilmente acessíveis nos periódicos científicos e demandam um esforço de busca em meios não tradicionais, que apresentam por sua vez múltiplos e conflitantes olhares sobre o fenômeno. Acesso direto aos artistas é restrito e são poucos os relatos em primeira mão. Uma exceção é, no entanto, a notável compilação de entrevistas com artistas de rua no livro Beyond the Street (NGUYEN \& MACKENZIE, 2010).

Estudar a história do espectador de arte, como sugere Almenberg (2010), e não só a do artista pode contribuir para a melhor compreensão do alcance e possibilidades da arte de rua. Nesse sentido é importante em primeiro lugar pesquisar a percepção da população a respeito das manifestações artísticas de rua para em segundo lugar saber se a intenção do artista alcança o público e de que forma é feita a apropriação desta arte pelo espectador, indicando ainda se ela modifica ou não a relação de apropriação deste espectador com o espaço público. Neste esforço são necessários estudos autóctones que levem em consideração a singularidade das cidades brasileiras e suas expressões artísticas, pois se a arte de rua é eminentemente situacional, sua compreensão deve ser feita a nível local.

Na escassez de práticas participatórias de planejamento e gestão de espaços, e frente à carência de espaços democráticos, o grafite se coloca como alternativa para a apropriação do espaço público urbano, não só para o autor desta arte, mas também para o público, na medida em que este se posiciona frente à obra, desperta para os condicionamentos que a cidade impõe e passa a participar da confecção do espaço de forma mais crítica, transformando-o em lugar.

\section{Referências}

ABARCA, J. Teaching urban intervention, learning to see the city anew. Urbanario: graffiti and street art. Madri, may, 2011. Disponível em:

<http://www.urbanario.es/en/articles/article/art/teaching-urban-intervention-learning-to-see-the-city-anew/>. Acesso em: 30 julho 2015.

ALMENBERG, G. Notes on participatory art. Toward a Manifesto differentiating it from open work, interactive art and relational art. Milton Keynes: AuthorHouse UK, 2010.

BOURRIAUD, N. Estética relacional. São Paulo: Martins Editora, 2009.

\section{POLÊM!CA | Revista Eletronica da Ueij}


CAMPOS, R. Movimentos da imagem no Graffiti. Das ruas da cidade para os circuitos digitais. Actas do VI Congresso Português de Sociologia - Mundos Sociais, Saberes e Práticas, Lisboa, n.98, 2008. Disponível em: 〈http://aps.pt/vicongresso/pdfs/98.pdf>. Acesso em: 10 março 2015.

CARR, S., FRANCIS; M., RIVLIN, L.G.; STONE, A.M. Public Space. Cambridge: Cambridge University Press, 1992.

CAVALCANTE, S.; ELIAS, T.F. Apropriação. In: CAVALCANTE, S. \& ELALI., G. (Orgs.). Temas básicos em psicologia ambiental. Petrópolis: Vozes, 2011. p. 63-69.

CHANG, C. (2011). Before I die [Post de Blog]. Disponível em: 〈http://candychang.com/before-i-die-in-nola〉. Acesso em: 17 dezembro 2011.

COCCHIARALE, F. A (outra) arte contemporânea brasileira: intervenções urbanas micropolíticas. In: ROSAS R.; SALGADO, M. Rizoma.net. Artefato. 2002, p. 8-12.

MANCO, T. Street Logos. London: Thames \& Hudson, 2004.

MANCO, T.; ART., L.; \& NEELON, C. Graffiti Brasil. NY: Thames \& Hudson, 2005.

NGUYEN, P.; MACKENZIE, J. (Eds.). Beyond the street. Berlin: Gestalten, 2010.

PIXO. Documentário sobre pichação e pichadores. Produção de Oliveira, R. T. Brasil: Sindicato Paralelo Filmes, 2009.

ROSAS, R. (Ins)urgência. In: ROSAS R.; SALGADO, M. Rizoma.net. Artefato. 2002, p. 8-12.

SENO, E. (Ed.). Trespass. A history of uncomissioned urban art. Köln: Taschen, 2010.

SILVA, A. Punto de vista ciudadano. Focalización visual y puesta en escena del graffiti. Bogotá: Publicaciones del Instituto Caro y Cuervo, 1987.

SILVEIRA, F.L. Grafite revisitado. Estética e comunicação de rua em Porto Alegre. Arquiteturarevista, São Leopoldo/RS, v.2, n.1, p.11-21, jan-jun, 2006.

Outros grafites. Outras topografias, outras medialidades. In: CAMPOS, R.; BRIGHENTI, A.;

SPINELLI, L. (Org.). Uma cidade de imagens. Produções e consumos visuais em meio urbano. Lisboa: Mundos Sociais, 2011, p.123-138.

TÚMULOS. Posts de blog. Entrevistas do Caixão. Entrevistas com pichadores. Disponível em: $<$ http://entrevistastumulos.blogspot.com>. Acesso em: 20 março 2015.

Recebido em: 27/05/2015.

Aceito em: 04/08/2015. 